\title{
Método geotecnológico integrativo na caracterização de solos desenvolvidos de diferentes materiais de origem
}

\author{
José A. M. Demattê $\left({ }^{*}\right)$; Rodnei Rizzo $\left({ }^{2}\right)$; Marco Antonio M. Bortoletto $\left(^{2}\right)$ \\ (') Escola Superior de Agricultura 'Luiz de Queiroz' (ESALQ/USP), Departamento de Solos e Nutrição de Plantas, Caixa Postal 9 , \\ 13418-900 Piracicaba (SP). \\ (2) ESALQ/USP, Programa de Pós-graduação em Solos e Nutrição de Plantas, 13418-900 Piracicaba (SP). \\ (*) Autor correspondente: jamdemat@esalq.usp.br
}

Recebido: 24/jun./2010; Aceito: 1.o/fev./2011

\section{Resumo}

O conhecimento do solo é um aspecto essencial para a aplicação de manejo adequado da cultura. Conciliar a pedologia ao desenvolvimento tecnológico é essencial para o progresso desta ciência. O presente trabalho tem por objetivo avaliar o uso de produtos do sensoriamento remoto conciliados a um sistema de informações geográficas, na caracterização de solos da região de Piracicaba. Para tanto, incursões a campo e coleta de dados em laboratório foram realizadas. Posteriormente, compilaram-se informações referentes a características qualitativas de rede drenagem e relevo utilizando-se estereoscopia em fotografias aéreas. Características quantitativas de altimetria e declividade através de modelo numérico de terreno, além de características espectrais para os diferentes solos e texturas obtidas a partir de imagens do Landsat 7. Tal metodologia resultou em um banco de dados, no qual se notam diferenças entre todos os solos em pelo menos um dos aspectos avaliados. As características qualitativas da rede de drenagem diferenciaram os solos, não ocorrendo o mesmo com os parâmetros quantitativos de relevo. No caso, os Latossolos e Neossolo Quartzarênicos tiveram grande similaridade. Por outro lado, houve diferença entre as características espectrais destes solos. As características de altitude tiveram maior contribuição na diferenciação dos solos em relação ao parâmetro declividade. A avaliação integrada de informações geotecnologicas permite obter um panorama próximo à real classe do solo.

Palavras-chave: sensores, quantificação de atributos, agricultura de precisão.

\section{Geotechnologic method on the characterization of soils developed from different pattern materials}

\begin{abstract}
Soil knowledge is essential for implementing appropriate management in agriculture. It is necessary to conciliate pedology with technological development to persuade the progress of soil science. This study aims to evaluate the use of remote sensing products accomplished with a geographic information system in the characterization of soils from Piracicaba region. Field inspection and data collection were performed. Subsequently, information was compiled regarding the qualitative characteristics of drainage network and topography using aerial photographs. Quantitative characteristics of elevation and slope from digital elevation model and spectral characteristics related to soil texture acquired from Landsat 7 images were considered. This methodology resulted in a database, which showed significant differences between all soils in at least one aspect. The qualitative characteristics of the drainage network differentiated soils, although it did not happen with the quantitative relief parameters. In this case, the Oxisols and Quartzipsamments showed high similarity. Moreover, there were differences between the spectral characteristics of the soils. The characteristics of altitude were the major contributors in soil differentiation. Integrated assessment of geoinformation allowed more realistic scenery of soil classes.
\end{abstract}

Key words: sensors, attributes prediction, precision agriculture. 


\section{INTRODUÇÃO}

O Brasil é um país de dimensōes continentais, capaz de produzir alimentos de forma racional e sustentável. Assim, o uso intensivo dos solos demanda conhecimento aprofundado de suas características e propriedades, de forma que se estabeleça um planejamento racional e a definiçấo de técnicas de manejo prioritárias à sua exploração e conservação. Apesar da demanda da agricultura por mapas de solos, estes são escassos e muitas vezes ausentes para determinadas áreas. Concomitante a esta situação, está o fato do mapeamento ser um processo de alto custo, e segundo McBratney et al. (2003), lento e requerer análises laboratoriais subsequentes.

Tendo observado tal aspecto, Demattê (2001) descreve a importância da utilizaçấo de novas tecnologias, como o sensoriamento remoto (SR), no auxílio ao mapeamento. Odeh e Macbratney (2000), por sua vez, comprovaram que a utilização do sensoriamento remoto e técnicas estatísticas foram as mais eficientes e menos onerosas na avaliação de solos.

Segundo Andronikov e Dobrovolskiy (1991), constituintes do solo, tais como: matéria orgânica, material de origem, óxidos de ferro, umidade e tamanho de partículas, interfere diretamente na intensidade da reflectância. O uso da reflectância espectral como técnica para acessar os atributos do solo tem se tornado proeminente devido a sua velocidade e fácil obtenção. A imagem de satélite, como ferramenta do SR, obtém informaçóes da superfície do solo o que não permite sua classificação, orientando porém, as prováveis características de uma região.

Outro produto utilizado no mapeamento é a foto aérea, permitindo a execução de atividades como fotointerpretação e fotoanálise. A aerofoto constitui importante instrumento de apoio nos trabalhos de levantamento de solos, pois além de servir como mapa-base de campo, pode ser utilizada em interpretaçóes para fins pedológicos (Lueder, 1959). A técnica para esses fins, a fotopedologia, reduz sensivelmente o custo e o tempo de execução de levantamento de solos, com a vantagem de oferecer informaçôes adicionais (VINK, 1963), devido principalmente à estereoscopia e alta resoluçáo espacial.

A técnica mais difundida atualmente é a análise digital do terreno, sendo capaz de caracterizar a paisagem quanto aos atributos relacionados ao relevo. Moore et al. (1991), afirmam que o conhecimento da influência da conformação da superfície, declividade e drenagem na formação dos solos, permite ao pedólogo inferir as propriedades do solo. IRvin et al. (1997), citam o estudo da paisagem voltado para a caracterização de solos, como meio de relacionar os processos ocorrentes no ambiente, a topografia e o desenvolvimento do solo. Logo, além de ser uma ferramenta capaz de avaliar o relevo, através do modelo digital de terreno (MDT), é uma alternativa rápida e econômica. Esta permite a definição semiautomática das unidades morfológicas da paisagem (Ippoliti et al., 2005).

Observa-se em literatura que inúmeros trabalhos são realizados na caracterização de solos por relevo e rede de drenagem. Com o surgimento do sensoriamento remoto espectral, outros trabalhos chegam a caracterizar os solos pela energia refletida. No entanto, há carência destas informaçôes de maneira integrada, que venham contribuir em maior detalhamento sobre o alvo em estudo. Portanto, o trabalho tem por objetivo caracterizar solos desenvolvidos de diferentes materiais de origem por técnicas de geoprocessamento e sensoriamento remoto. Os objetivos específicos são caracterizar solos da região: pelo método tradicional; quanto aos aspectos de paisagem pela utilização de fotografias aéreas; por imagens de satélite; quanto à sua relaçáo com a declividade e altitude por modelos digitais de terreno.

Como hipótese, espera-se observar solos com diferentes características morfopedológicas e de forma diferenciada quanto às informaçôes obtidas pelas diferentes técnicas como relevo, altitude, rede de drenagem, características espectrais, entre outras. Espera-se que a convergência de evidências leve ao melhor resultado da classe do solo.

\section{MATERIAL E MÉTODOS}

\section{Área de estudo e base de solos}

A área do estudo localiza-se no Estado de São Paulo, região de Piracicaba, entre as latitudes 22042'49” - 230' $15^{\prime \prime}$ Sul e longitude 47057'3" - 47030'15" Oeste, detendo uma área total de 30.000 ha. O clima é o CWA (Köppen), tropical com inverno seco e verão chuvoso. A precipitaçáo pluvial média anual é de $1.200 \mathrm{~mm}$, e a temperatura média é de $21,4^{\circ} \mathrm{C}$. O mapa base de solos utilizado para este trabalho foi a quadrícula de Piracicaba nível semidetalhado (Figura 1a) (Oliveira et al., 1989) e tem como principais solos o Neossolo Quartzarênico (RQ), Neossolo Litólico (RL2), Latossolo Vermelho-Amarelo (LV1, LV2 e LV5) e Argissolo Vermelho-Amarelo (PV4, PV5, PV7, PV9)

\section{Passos metodológicos}

Foram escolhidas quatro áreas dentro da quadrícula (Figura 1a), obtendo assim heterogeneidade de solos conciliada à representatividade da regiáo. Em seguida, incursóes a campo foram realizadas para melhor identificação das unidades de mapeamento. Para tanto, foram analisadas e descritas as características morfológicas de 12 perfis de solos, sendo os de maior relevância o Latossolo Vermelho-Amarelo, o Neossolo Litólico e o Argissolo Vermelho Abruptico típico (Embrapa, 2006). Durante a descrição morfológica, seguiram-se os padróes especificados por 


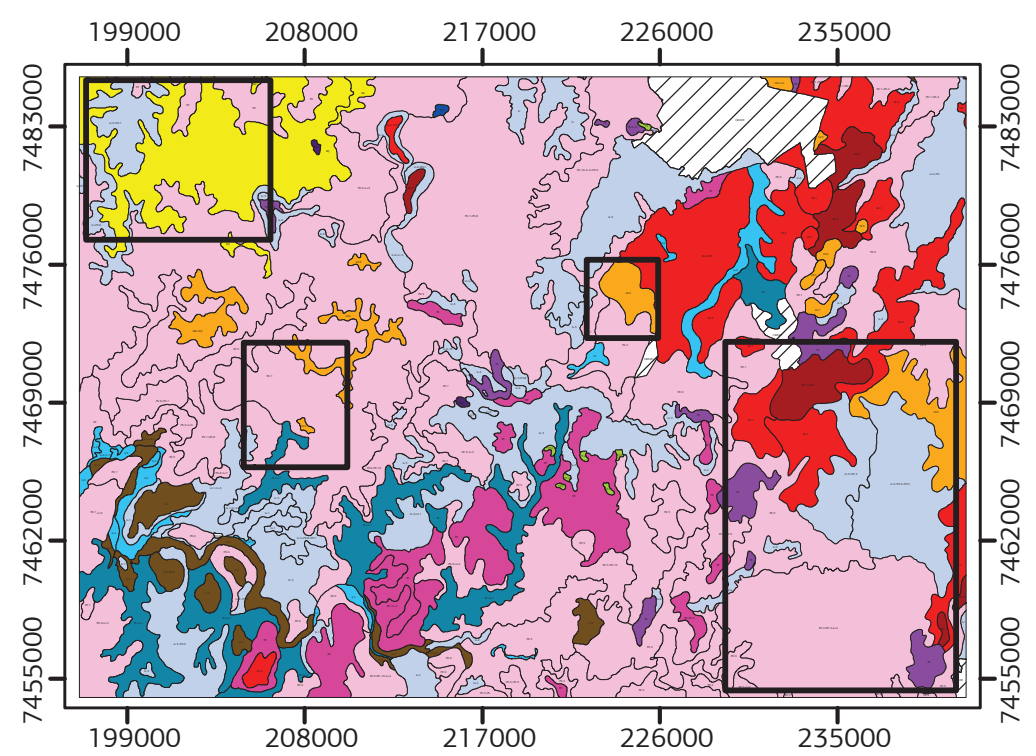

Legenda

(a)
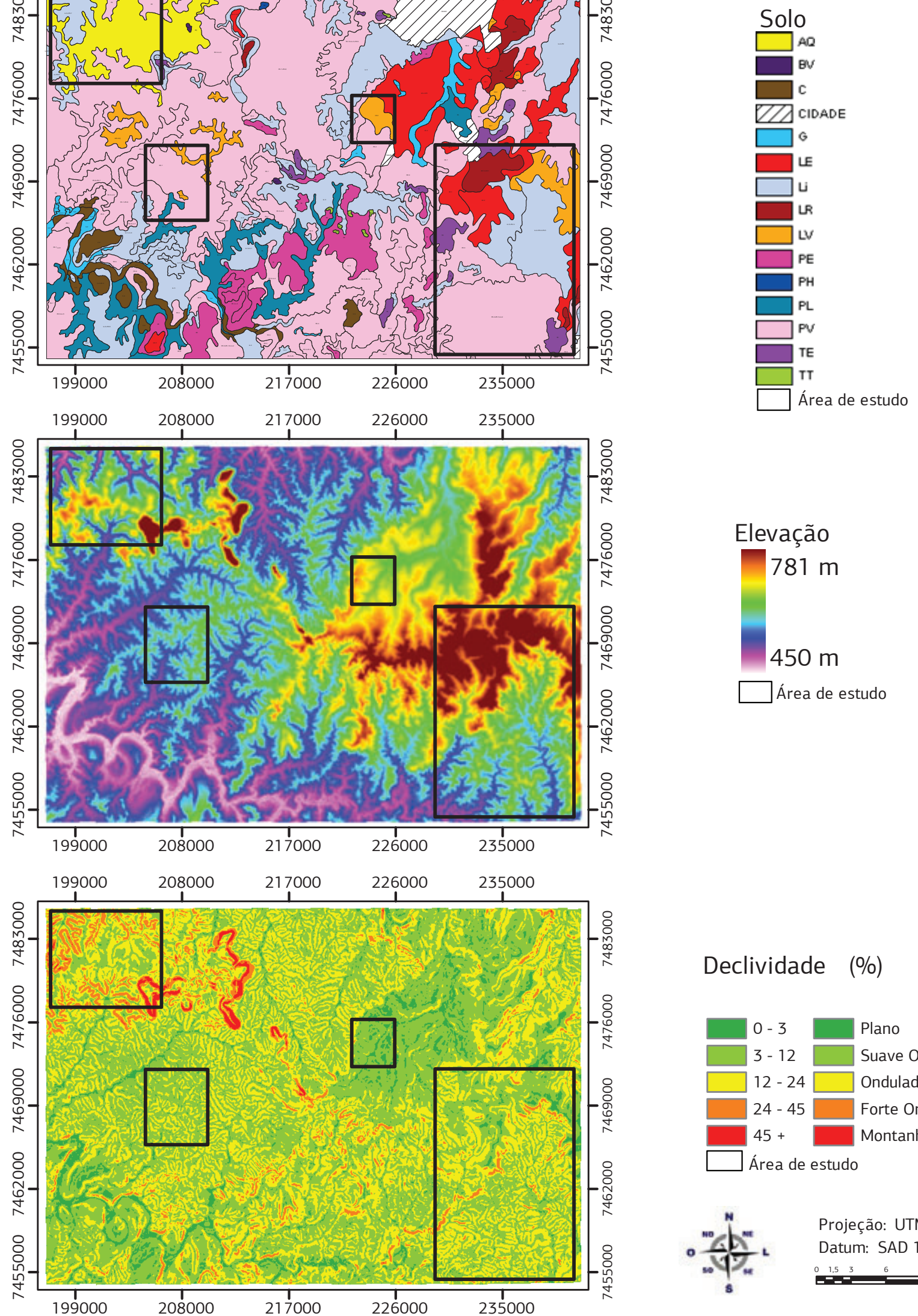

Figura 1. Ilustração dos mapas de (a) solos semidetalhado (Quadrícula Piracicaba) (Oliverra et al. 1989), (b) altimetria e (c) declividade, referente às áreas de estudo. 
SANTOS et al. (2005), atentando também a paisagem ao seu redor. Foram realizadas amostragens pontuais através de tradagens, perfazendo um total de 178 pontos coletados com trado, nas profundidades $0-20,40-60$ e 80-100 $\mathrm{cm}$. Em todos os locais de coleta, perfis ou observaçôes, realizou-se o georreferenciamento com GPS.

Em seguida, as análises granulométrica (CAMARgo et al., 1986), química ( $\mathrm{pH}$ em água e $\mathrm{KCl}, \mathrm{Ca}^{2+}, \mathrm{Mg}^{2+}, \mathrm{Al}^{3+}$, $\mathrm{H}^{+}+\mathrm{Al}^{3+}$ ) e de matéria orgânica (MO) (RAIJ e Quaggio, 1989) foram realizadas. A partir desses dados, obteve-se o valor da soma de bases $(S)$, capacidade de troca catiônica (CTC), saturação por bases (V\%) e saturação por alumínio $(\mathrm{m} \%)$. A cor da amostra úmida foi obtida utilizando-se um colorímetro minolta CR - 300, com chip para cor Munsell, seguindo metodologia de Campos e Demattê (2006).

\section{Caracterização da rede de drenagem e relevo}

Foram adquiridas fotografias aéreas preto e branco na escala 1:25.000 de toda a região de estudo, do período de junho a agosto de 1972. Em seguida, estas fotos foram organizadas a fim de forma a se obter um mosaico da regiáo, possibilitando a escolha das localidades, com padróes de drenagem distintos, que constassem na carta de solos semidetalhada de Oliveira (1989). A partir daí, os pares estereoscópicos foram separados e afixado o papel vegetal sobre as fotografias. O passo seguinte consistiu em realizar observaçôes no equipamento, delimitando o traçado dos canais de drenagem. Todas as fotos foram escaneadas $\mathrm{e}$ georreferenciadas. A rede de drenagem foi posteriormente digitalizada e introduzida no banco de dados no programa ArcGis 9.2 (ESRI, 2004). A caracterização da rede de drenagem e relevo foi realizada segundo Lueder (1959). Por fim, a sobreposiçáo do mapa de solos da região permitiu obter os padróes de cada um.

\section{Obtenção dos mapas de elevação e declividade}

Para a análise digital do terreno foi obtido um MNT (Modelo Numérico do Terreno), sendo esta informação advinda da Shuttle Radar Topography Mission (SRTM) e disponibilizada pela EMBRAPA (MirAndA, 2009). Tal informação consiste em uma imagem com resolução espacial de $90 \mathrm{~m}$. O trabalho utilizou atributos primários derivados do MNT (Moore et al., 1991) que permitiu a caracterizaçáo de elementos da paisagem relacionados com os processos de formação do solo. Assim, avaliaramse dois mapas, sendo um de altitude (modelo de elevação) (Figura 1b) e outro de declividade classificada de acordo com Santos et al. (2005) (Figura 1c). Posteriormente, foi realizado o cruzamento do mapa de solos com os de declividade e altimetria obtendo-se os respectivos valores máximos, médios e mínimos de cada classe de solo.

\section{Dados espectrais}

Foram adquiridas as características espectrais da superfície do solo, através de uma imagem do sensor ETM/Landsat 7 (Enhanced Thematic Mapper), referente a 22 de outubro de 2002, devidamente corrigida atmosfericamente e transformada para valores de reflectância (TANRÉ ET AL., 1992).

Em seguida, tendo como alvo os locais de amostragem de solos, observou-se na imagem quais deles localizaramse em áreas de solo exposto. Para tanto, foi utilizada o método descrito por Demattê et al. (2001), o qual implica a avaliação de vários fatores em simultâneo, entre eles, o índice de vegetação, imagens de composição colorida, linha do solo e observação das curvas espectrais na imagem.

A caracterização das áreas com solo exposto teve por objetivo avaliar dois aspectos: (a) o comportamento das curvas espectrais de acordo com a textura e classe de solo; (b) a realização de equaçóes de quantificação do teor de argila por dados espectrais orbitais.

Para adquirir as características do tópico (a), primeiramente, os dados espectrais de cada ponto amostral foram coletados e inseridos em banco de dados em conjunto com as análises de solo realizadas em laboratório. Em seguida, os pontos foram avaliados quanto às diferentes classes texturais $\left(\mathrm{g} \mathrm{kg}^{-1}\right)$, classificadas como: arenosa $(<$ 150), média-arenosa (150 a 250), média-argilosa (250 a 350 ) e argilosa ( 350 a 600), perfazendo um total de 148 pontos na fase de calibração. Essas amostras foram utilizadas como base para a classificação supervisionada na imagem de satélite, utilizando o classificador correspondente a "máxima verossimilhança" (Richards, 1999). A validação da técnica foi através da checagem de campo em 30 pontos diferentes gerando uma matriz de erro e acerto. O passo seguinte foi a obtenção das curvas espectrais de cada classe textural para posterior caracterizaçáo. Para a determinação das curvas espectrais padrôes, cada ponto de tradagem foi previamente classificado quanto ao solo a que pertencia. Posteriormente, foi realizada a coleta dos dados de reflectância e cálculo da reflectância média das diferentes bandas para cada solo em questáo.

\section{RESULTADOS E DISCUSSÃO}

\section{Caracterização dos solos}

O perfil 1, durante a análise morfológica (Tabela 1), foi subdividido em quatro horizontes, sendo eles, Ap, Bw1, $\mathrm{Bw} 2$ e $\mathrm{Bw} 3$, os quais estavam respectivamente, nas profundidades $(\mathrm{cm})$ de 0 a 25,25 a 80,80 a 130 e mais que 130 . 


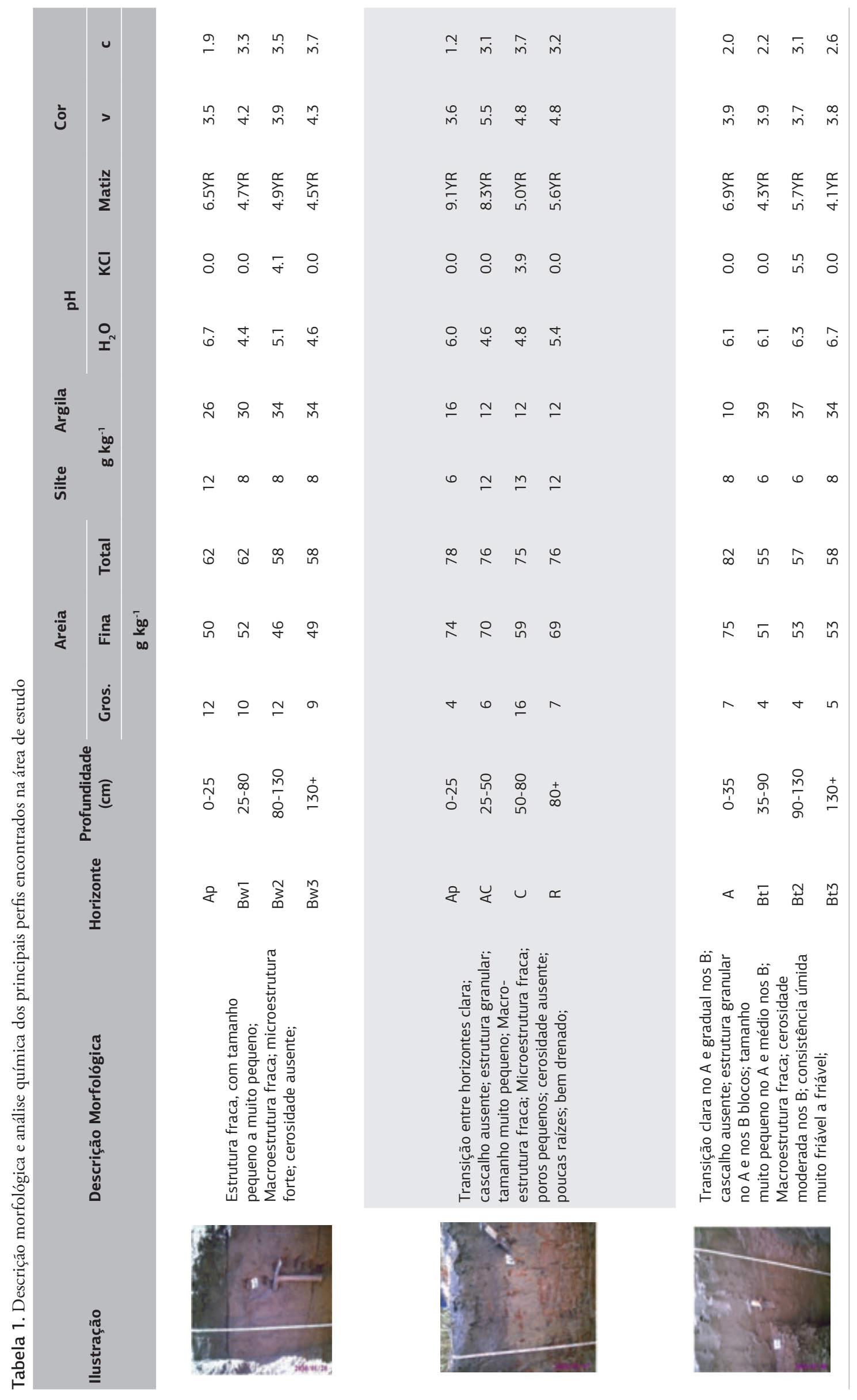


A este solo foram atribuídos os seguintes aspectos, alta porosidade presente nos horizontes $\mathrm{Bw}$, a estrutura granular e microestruturação forte. A obtenção da cor, através do colorímetro, gerou valores próximos a 5YR, confirmando a subordem vermelho-amarelo. A partir de análise química, constatou-se a baixa saturação de bases, implicando assim no caráter distrófico e o valor de $\mathrm{pH}$ na faixa de 4,5 a 5. Por fim, a análise granulométrica explicitou, a textura médio-argilosa do solo, a ausência de gradiente textural e a relação silte/argila abaixo de 0,6, e, complementando, a isto está o fato do relevo local ser suave ondulado. Portanto, tendo em vista a caracterização feita para este perfil, concluiu-se que corresponde a um Latossolo VermelhoAmarelo distrófico, textura média argilosa.

$\mathrm{Na}$ análise morfológica do perfil 2 (Tabela 1), quatro horizontes foram delimitados, sendo eles, Ap, AC, C e $\mathrm{R}$, os quais estavam respectivamente, na profundidade de 0 a $25 \mathrm{~cm}, 25$ a $50 \mathrm{~cm}, 50$ a 80 e mais que $80 \mathrm{~cm}$. É importante ressaltar que havia o contato lítico à profundidade de $50 \mathrm{~cm}$ e, além disso, a ocorrência de alagamento devido ao mesmo. Observando-se a análise química e granulométrica, constatou-se que a textura ocorrente era arenosa, a relação silte/argila em torno de 1,0 e a presença do caráter alumínico, somando-se a tais fatores, conclui-se que a localidade era de relevo ondulado. Compilando-se tais informaçóes, concluiu-se que o solo em questão era Neossolo Litólico, textura arenosa, alumínico.

Por fim, no perfil 3 constataram-se quatro horizontes, os quais correspondiam ao Ap, Bt1, Bt2 e Bt3, estando localizados à profundidade de 0 a $35 \mathrm{~cm}, 35$ a $90 \mathrm{~cm}$, 90 a $140 \mathrm{~cm}$ e maior que $140 \mathrm{~cm}$ respectivamente. Os principais aspectos atribuídos a este solo foram a transição clara do horizonte A para o B, gradiente textural abrupto, a cor úmida 4,3 YR, a estrutura em blocos no B textural com tamanho médio, além da macroestrutura forte e a cerosidade moderada. Neste caso, a análise granulométrica expôs o que já havia sido visto em campo, ou seja, gradiente textural abrupto $(3,8)$, textura argilosa e complementar a isto, características como a alta saturação por bases e $\mathrm{pH}$ na faixa de 6,0. Por estes caracteres, chegou-se ao consenso de que a descriçáo correspondia ao Argissolo Vermelho-Amarelo abrupto, textura argilosa, eutrófico.

\section{Caracterização da rede drenagem}

Os modelos de canais observados na região de estudo foram basicamente os paralelos, subparalelos, dendríticos e subdendríticos (Tabela 2). A partir daí, observa-se que o Neossolo Quartzarênico (RQ), o Latossolo VermelhoAmarelo (LV2) e a classe associada de Neossolo Litólico e Argissolo (RL3 + PV9) possuem drenagem com modelo subparalelo, enquanto o Latossolo Vermelho (LE1+LE2), um modelo paralelo. Já o tipo classificado como subdendrítico teve ocorrência exclusivamente na associação entre
Neossolo Litólico e Argissolo (RL2+PV4+PV5). Por fim, os Argissolos (PV7; PV4+PV5+RL2) foram as classes que tiveram drenagens dendríticas, concordando assim com Angulo Filho (1986), o qual deteve o mesmo resultado ao caracterizar diferentes Argissolos Vermelho-Amarelo da Região Centro-Oeste de São Paulo.

Demattê et al. (1993), ao estudar as características da rede de drenagem para alguns solos situados próximos aos municípios de Santa Bárbara D`Oeste e Americana, obteve resultados semelhantes quanto às classes do Latossolo Vermelho-Escuro e Argissolo. Discordando, porém, quanto àquela referente ao Neossolo Litólico, caracterizando-a como dendrítico.

Quanto ao grau de integração todas as unidades classificadas tiveram um índice considerado alto, com exceção do Latossolo Vermelho (LE1+LE2), no qual havia áreas onde os canais de drenagem tinham seu curso interrompido.

A densidade de drenagem, como já era esperado, demonstrou valores baixos em solos bem drenados (RQ, LV2, LE1+LE2). Este fato ocorre, pois há uma taxa de infiltração muito maior que o deflúvio, gerando menor número de cursos d'água. Nos Argissolos (PV7 e PV4+PV5+RL2), a presença do horizonte $B$ textural acarreta menor infiltração e maior deflúvio, pois funciona como uma barreira de impedimento. Tais características decorrentes do processo morfogenético acabam refletindo nos padróes de drenagem, e consequentemente nas suas densidades (Christofoletti, 1974). Esse processo se deve ao fato de os Latossolos terem maior permeabilidade e, portanto, uma drenagem menos dissecada (Demattê e Demétrio, 1996a,b). Em conformidade com este fato estão França e DematTê (1990), que ao avaliarem a densidade de drenagem (Dd) para Latossolos Vermelho-Escuros (LE1 e LE2) e Argissolos Vermelho-Amarelos (PV1, PV2, PV3 e PV4), observaram que a Dd praticamente duplicou. Além disso, obtiveram valores de densidade muito próximos, quando analisadas as classes LE e RQ.

Outra classe que detém alto índice de densidade são os Neossolos Litólicos, explicada pela sucessão do horizonte A pelo horizonte $\mathrm{C}$ e em seguida pela rocha.

Já o grau de uniformidade foi alto, exceto nas unidades associadas LE1+LE2 e RL3+PV9. No primeiro caso, respectivamente, tal valor é devido ao tamanho reduzido da área avaliada. No segundo caso, o fato da unidade de mapeamento ser uma associação teria afetado. Demattê et al. (1993), ao avaliar a mesma característica, utilizando amostragem circular, afirmaram que a associação Neossolo Litólico e Argissolo era pouco uniforme, aproximandose assim do resultado obtido neste trabalho.

Os solos estudados, com exceção da classe RL2+PV4+PV5, tiveram valor baixo ou mesmo ausência de controle. A classe discrepante na análise é justificada pela presença da rocha em um patamar muito próximo a superfície. Ligado ao grau de controle está a angularidade, aspecto que exibe à presença ou não de mudanças 
abruptas no sentido de caminhamento do canal devido à presença de rochas. Nota-se que, a única classe de solo que detém valor médio a alto é o RL2+PV4+PV5, concordando assim com Parvis (1950) e Lueder (1959), os quais citaram o controle que pode ocorrer devido ao substrato rochoso.

A orientação, por sua vez, estava ausente apenas na unidade constituída pelo Argissolo, ou unidades com predominância deste solo, tendo relaçáo provavelmente com o modelo dendrítico de tais unidades de mapeamento.

Por fim, os ângulos de confluência, os quais são observados na intersecção do canal tributário com o canal receptor, foram classificados retos para todos os Latossolos e Neossolos Litólicos, enquanto os Argissolos e o Neossolo Quartzarênico possuem conformação aguda.

\section{Caracterização qualitativa do relevo}

A distinçâao das unidades de mapeamento quanto ao relevo (Tabela 3), os solos bem drenados, Latossolos e Neossolos Quartzarênicos, é do tipo normal e classe plana a suave ondulada; este segundo aspecto concorda com os resultado obtidos por Souza Junior e Demattê (2008), os quais correlacionando dados de declividade e solos da região de Ibaté (SP), verificaram que os Latossolos estáo em declividades de até $10 \%$. A uniformidade e o gradiente também eram semelhantes entre LV, LE e RQ, os diferenciando apenas na forma da vertente, a qual é convexa para Latossolos e reta para o Neossolo Quartzarênico. CAmpos et al. (2007), ao estudar a relação solo-paisagem na região de Pereira Barreto, São Paulo, cita o formato convexo dos Latossolos na regiáo e, portanto, concordando com o presente trabalho.

Os Neossolos Litólicos e Argissolos tiveram classificações de relevo parecidas, e em todos os casos o tipo foi considerado excessivo e a classe ondulada ou forte ondulada. Também se observou semelhança no comprimento da vertente, sendo este médio. Contudo, o ponto-chave na separação entre estes dois solos está na uniformidade e no gradiente, os quais são, respectivamente, pouco uniforme e forte a muito forte para Neossolos, e uniforme e moderado para Argissolos. Demattê et al. (1993), de forma geral, obteve resultados muito próximos aos deste estudo no que diz respeito a características do relevo; os caracteres discrepantes foram: a forma da vertente dos Neossolos Litólicos, a qual foi considerada mista pelo autor, e a uniformidade para os PVs, os quais são irregulares.

\section{Caracterização quantitativa do relevo}

Em geral, as altitudes máximas médias e mínimas das diferentes classes de solo tiveram diferenças (Tabela 4). Observou-se nos Latossolos menor variação de altitude, exceto para a classe do LE1 + LE2, verificada em locais mais altos, com uma faixa de variação de 112 metros. Tais dados concordam com LePSCH et al. (1977) que, estudando a regiáo de Echaporã (SP), obtiveram resultados semelhantes, identificando Latossolos nas partes mais altas e planas da paisagem.

O Neossolo Quartzarênico, dentre todos foi aquele com maior amplitude de altitudes (154 metros). Este resultado concorda com Souza Junior (2006) e Prado (2005), quando afirmaram que a posição de determinados solos pode variar, não ocorrendo em uma faixa especifica de altitude.

As classes de solo constituídas pelos Argissolos ou associações com predominância deste último não tiveram nenhum padrão marcante quanto à variação de altitude, assemelhando-se somente quanto à altitude mínima que ficou na faixa de 482 a 495 metros.

$\mathrm{Na}$ declividade não houve feiçôes características que pudessem distinguir por si só as unidades de mapeamento, com exceção para o Latossolo, com declividades médias de $3 \%$ a $6 \%$ e máxima de $19,15 \%$. Tais valores médios já haviam sido descritos por Oliveira et al. (1992). Reis et al. (2004), utilizando-se também técnicas de geoprocessamento para uma investigaçáo detalhada de relacionamento entre relevo e classe de solo no município de Bandeiras, Paraná, verificaram que $37.4 \%$ dos LVs da área em estudo estavam entre 0 e $3 \%$ de declividade, contudo, encontraram tal classe posicionada em locais de relevo de até $20 \%$ de declividade.

Devido ao fato de Argissolos e Neossolos Litólicos estarem muitas vezes associados no estudo, dificultou uma distinção entre os dois. O Neossolo Quartzarênico, por sua vez, tinha maior variabilidade, ocorrendo em locais planos e áreas com até 30\% de declividade.

\section{Características espectrais dos solos}

As curvas espectrais médias por grupamento textural (Figura 2a) foram distintas. Observa-se maior variação na intensidade de reflectância, a partir da banda 2, em decorrência da textura arenosa e provavelmente da umidade. Demattê et al. (2000) também observaram pico de intensidade de reflectância acentuado nos solos com textura arenosa, quando comparados aos de textura argilosa.

$\mathrm{Na}$ banda 5, todas as curvas atingiram o valor de intensidade de reflectância máximo, em sentido decrescente na direçấo da banda 7 . Tal fato relaciona-se à maior absorção da energia eletromagnética, decorrente dos minerais de argila (Al AbBas et al., 1972).

O processo de avaliação e espacialização de textura de solos, por meio da imagem de satélite, é funcional no delineamento das classes de textura, contudo, notase uma confusão entre as classes. Principalmente entre as classes argilosa $\left(350-600 \mathrm{~g} \mathrm{~kg}^{-1}\right)$ e média argilosa $(250$ - 
Tabela 2. Características qualitativas da rede de drenagem para as diferentes classes de solo

\begin{tabular}{lcccccccc} 
Características & RQ & LE1+LE2 & RL2+PV4+PV5 & RL3+PV9 & LV2 & LV5* & PV7 & PV4+PV5+RL2 \\
\hline Tipo ou Modelo & Subparalelo & Paralelo & Subdentrítico & Subparalelo & Subparalelo & - & Dendrítico & Dendrítico \\
Grau de Integração & Alto & Médio & Alto & Alto & Alto & - & Alto & Alto \\
Densidade & Baixa & Baixa & Média/Alta & Alta & Baixa & - & Alta & Alta \\
Grau de Uniformidade & Alto & Médio & Alto & Médio & Alto & - & Alto & Alto \\
Grau de Controle & Ausente & Ausente & Alto & Baixo & Baixo & - & Ausente & \\
Orientação & Orientado & Orientado & Pouco Orientado & Orientado & Orientado & - & Não Orientado Não Orientado \\
Angularidade & Ausente & Baixa & Média/Alta & Baixa & Baixa & - & Ausente & Baixa \\
Ângulos de confluência & Agudo & Reto & Reto & Reto & Reto & - & Agudo & Agudo
\end{tabular}

(1) Nomenclatura de acordo com mapa (Oliverra e Prado 1989). * Ausência de padróes.

Tabela 3. Características qualitativas do relevo para as diferentes classes de solo

\begin{tabular}{|c|c|c|c|c|c|c|c|c|}
\hline \multirow{2}{*}{$\begin{array}{l}\text { Elemento } \\
\text { Analisado }\end{array}$} & \multicolumn{8}{|c|}{ Solos (') } \\
\hline & RQ & LE1 + LE2 & RL2+PV4+PV5 & RL3+PV9 & LV2 & LV5 & PV7 & PV4+PV5+RL2 \\
\hline Tipo & Normal & Normal & Excessivo & Excessivo & Normal & Normal & Excessivo & Excessivo \\
\hline Classe & Suave ondulado & Suave ondulado & Ondulado & Forte ondulado & Plana & Plano & ondulado & Ondulado \\
\hline $\begin{array}{l}\text { Forma da } \\
\text { Vertente }\end{array}$ & Reta & Convexa & Concava & Concava & $\begin{array}{l}\text { Convexa/ } \\
\text { reta }\end{array}$ & - & Convexa & Côncava \\
\hline $\begin{array}{l}\text { Comprimento } \\
\text { da Vertente }\end{array}$ & Muito longa & Muito longa & Média & Média & $\begin{array}{l}\text { Muito } \\
\text { longa }\end{array}$ & Uniforme & $\begin{array}{l}\text { Muito } \\
\text { longa }\end{array}$ & Média \\
\hline Uniformidade & Uniforme & Uniforme & Pouco uniforme & Pouco/ Uniforme & Uniforme & - & Uniforme & Uniforme \\
\hline Gradiente & Suave & Suave & Forte & Muito forte & Suave & - & Moderada & Moderado \\
\hline
\end{tabular}

(') Nomenclatura de acordo com mapa (Oliverra e Prado 1989).

Tabela 4. Valores máximo, médio e mínimo de declividade e altimetria de cada unidade de mapeamento

\begin{tabular}{|c|c|c|c|c|c|c|}
\hline Solos & Área & Min & Max & Intervalo & Média & Desvio-padrão \\
\hline \multicolumn{7}{|c|}{ Altimetria } \\
\hline & $m^{2}$ & m & m & m & $m^{2}$ & \\
\hline RQ & 27214500,00 & 483,00 & 637,00 & 154,00 & 572,91 & 27,64 \\
\hline LE-1+LE-2 & 18863700,00 & 582,00 & 694,00 & 112,00 & 647,21 & 19,53 \\
\hline RL-2+PV-4+PV-5 & 19285000,00 & 523,00 & 652,00 & 129,00 & 573,96 & 27,30 \\
\hline $\mathrm{RL}-3+\mathrm{PV}-9$ & 14774600,00 & 534,00 & 660,00 & 126,00 & 590,70 & 28,42 \\
\hline LV-2 & 6230330,00 & 564,00 & 618,00 & 54,00 & 585,52 & 11,91 \\
\hline LV5 & 8164350,00 & 597,00 & 664,00 & 67,00 & 638,79 & 12,07 \\
\hline PV-4+PV-5+RL-2 & 16943500,00 & 482,00 & 586,00 & 104,00 & 538,86 & 20,38 \\
\hline PV-7 & 22068600,00 & 495,00 & 563,00 & 68,00 & 531,28 & 13,81 \\
\hline \multicolumn{7}{|c|}{ Declividade } \\
\hline & $\mathrm{m}^{2}$ & $\%$ & $\%$ & $\%$ & $\%$ & \\
\hline RQ & 27206900,00 & 0,00 & 30,81 & 30,81 & 7,74 & 4,08 \\
\hline LE-1 +LE-2 & 18863200,00 & 0,00 & 18,09 & 18,09 & 6,13 & 3,38 \\
\hline RL-2+PV-4+PV-5 & 19298300,00 & 0,30 & 25,98 & 25,68 & 8,15 & 4,11 \\
\hline $\mathrm{RL}-3+\mathrm{PV}-9$ & 14781100,00 & 0,21 & 24,67 & 24,46 & 8,15 & 4,20 \\
\hline LV-2 & 6237070,00 & 0,00 & 9,92 & 9,92 & 3,16 & 1,65 \\
\hline LV5 & 8143410,00 & 0,00 & 19,15 & 19,15 & 4,02 & 3,14 \\
\hline PV-4+PV-5+RL-2 & 16949900,00 & 0,21 & 19,13 & 18,92 & 7,05 & 3,16 \\
\hline PV-7 & 22068000,00 & 0,21 & 15,70 & 15,49 & 6,06 & 2,52 \\
\hline
\end{tabular}

Tabela 5. Validação da classificação supervisionada (percentagem de erro e acerto)

\begin{tabular}{|c|c|c|c|c|c|c|}
\hline \multirow{2}{*}{$\begin{array}{l}\text { Valores reais } \\
\left(\mathrm{g} \mathrm{kg}^{-1}\right)\end{array}$} & \multicolumn{5}{|c|}{ Valores estimados $\left(\mathbf{g ~ k g}^{-1}\right)$} & \multirow{2}{*}{ Total } \\
\hline & $>60$ & $35-60$ & $25-35$ & $15-25$ & $<15$ & \\
\hline$>60$ & - & - & - & - & - & \\
\hline $35-60$ & - & 25,00 & 58,33 & 16,67 & 0,00 & 100,00 \\
\hline $25-35$ & - & 0,00 & 38,46 & 38,46 & 23,08 & 100,00 \\
\hline $15-25$ & - & 0,00 & 20,69 & 51,72 & 27,59 & 100,00 \\
\hline$<15$ & - & 0,00 & 12,50 & 35,71 & 51,79 & 100,00 \\
\hline
\end{tabular}


(a)

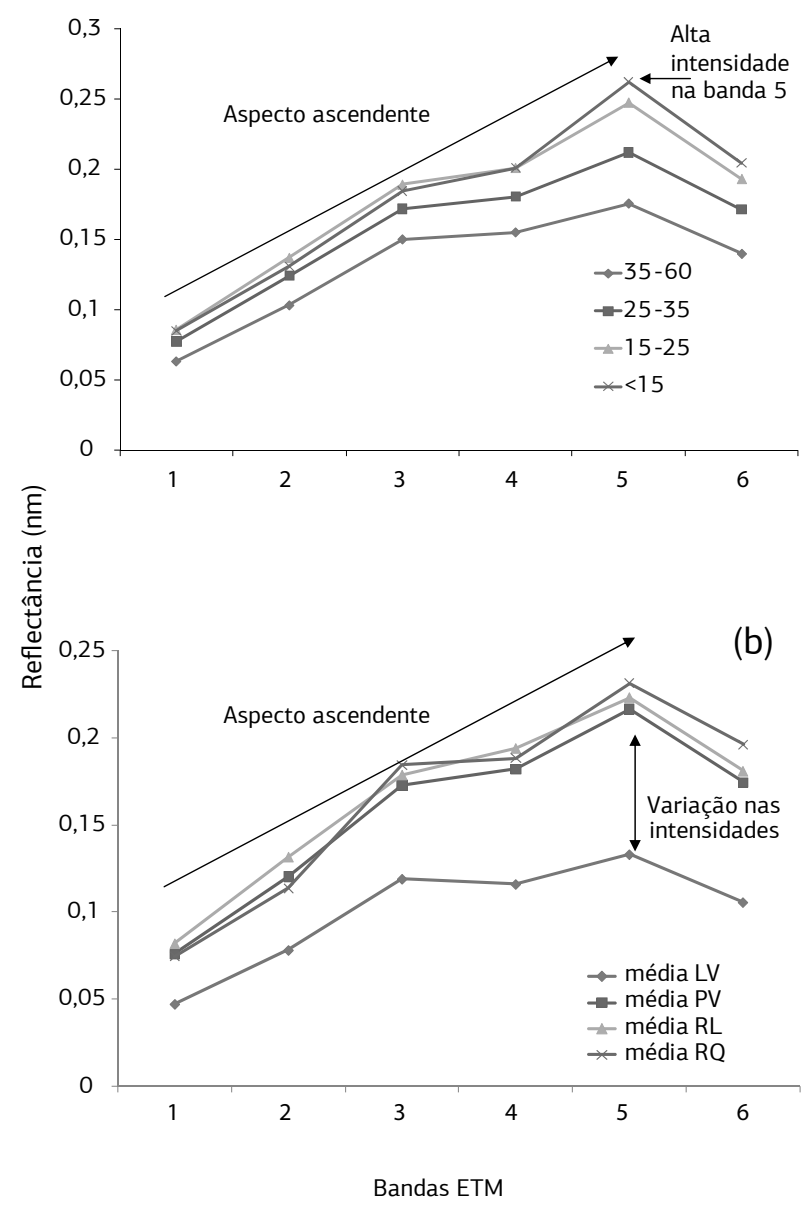

Figura 2. Curvas espectrais médias por grupamento textural obtidas do satélite LANDSAT 7 (a) e por classe de solo obtidas do satélite LANDSAT 7 (b).

$350 \mathrm{~g} \mathrm{~kg}^{-1}$ ), sendo que neste caso o classificador estimou $58,33 \%$ das amostras argilosas como média argilosas. No entanto, o inverso não ocorreu, ou seja, não houve confusão entre amostras de classe média com a classe argilosa (Tabela 5). É importante ressaltar que a textura média foi subdivida em média argilosa e média arenosa. Nesta situação o classificador confundiu as duas classes obtendo assim um acerto de $38,46 \%$ e confundindo outros $38,46 \%$ entre ambas as classes. Por outro lado, se consideramos a textura média como de $15 \%$ a $35 \%$, como é feita usualmente, o acerto chega a $81 \%$. Nas texturas mais arenosas, o acerto obtido foi maior, e tal aspecto correspondeu a mais do que 50\%. Esse valor concorda com Genu et al. (2010), que classificou a textura de solos da região de Rafard (SP), através de imagens de satélite AVIRIS, e obteve maior acerto para a classe arenosa.

Por fim, observa-se que não houve confusão entre classes de textura argilosa e arenosa, o que segundo MADeira Netto (2001), está relacionado ao fato de a textura afetar diretamente a resposta espectral do alvo, e quanto mais argilosa, menor será sua reflectância.
Com relação às curvas espectrais médias para as diferentes classes de solo (Figura 2b), observou-se variação devido aos constituintes de cada solo e sua influência no espectro. Para a banda 1 , tal diferença não foi tão expressiva, e todas as classes ficaram entre 0,047 para o LV e 0,076 para o PV. Nas bandas 3, 4, 5 e 7 a variação foi maior, e na banda 5 ocorreu a maior diversidade. No que diz respeito à feição da curva, o LV foi distinto das outras classes, com uma concavidade mais acentuada no intervalo entre as bandas 3 e 5 . Segundo NANNI (2000), corresponde ao maior teor de ferro no solo.

As curvas pertencentes ao PV, RL e RQ tiveram valor de reflectância mais elevado por todo o espectro. Tal fato está relacionado não só ao baixo teor de ferro, mas também à constituição física, tendo grande contribuição de partículas grosseiras.

\section{Interpretação associada das classes}

As técnicas de sensoriamento remoto já são utilizadas há algum tempo como auxílio no levantamento de solos, porém, geralmente, cada usuário utiliza um produto do SR em específico. Assim, há necessidade de metodologias que façam uso integrado de todas as informaçôes possíveis.

Este trabalho expóe a capacidade das técnicas integradas em distinguir diferentes classes de solo. $\mathrm{O}$ ponto chave é observar que em determinados casos somente uma ferramenta não é capaz de indicar diferenças, no entanto, conciliando-se o conhecimento do pedólogo a todos os dados, bons resultados são obtidos.

De forma geral, Latossolos e Neossolos Quartzarênicos possuem padróes similares quanto ao relevo, tanto em aspectos qualitativos quanto quantitativos. No entanto, os Latossolos (Figura 4) têm pontos mais altos e, além disso, ao se observar o espectro de ambos, sua composição físico-química diferenciada é evidente.

Os Argissolos e Neossolos Litólicos são semelhantes à RQ com relação ao comportamento espectral. Contudo, as características de relevo são diferenciadas. Além disso, há padrōes diferenciados entre PV e RL, principalmente quanto à conformação das redes de drenagem. Os Argissolos possuem forma dendrítica e localizando-se em regiốes mais baixas, já o RL possui padrão subparalelo e localiza-se em geral na meia encosta.

Dentre todas as ferramentas, a fotointerpretação deteve papel essencial, sendo um dos melhores produtos para estabelecimentos de relaçôes geomorfológicas. Além disso, com a evolução da estatística e dos métodos computacionais, há grande potencial no mapeamento digital de solos.

A imagem de satélite Landsat 7 é válida em uma primeira instância, para reconhecimento de padrôes na área. Contudo, seu reduzido número de bandas restringe a precisão da mesma. 
Os modelos de elevação e declividade são indicativos de mudança das classes de solo, no entanto, em diferentes áreas ocorre distribuição distinta do solo na toposequência. Assim, é mais apto ao delineamento de unidades de solo.

\section{CONCLUSÃO}

Os métodos de forma isolada não são capazes de distinguir as diferentes classes de solo. No entanto, ao realizar-se uma interpretaçáo associando todas as informaçôes surgem certos padrōes.

O Neossolo Quartzarênico e o Latossolo VermelhoAmarelo possuem drenagem com modelo subparalelo, enquanto o Latossolo Vermelho, modelo paralelo. O Neossolo Litólico associado ao Argissolo, subdendrítico. A classe dos Argissolos possue drenagem dendrítica. Os Latossolos detiveram menor variação de altitude. O Neossolo Quartzarênico compôe-se de maior variaçáo de altitudes, e a declividade não tem feições características que pudessem distinguir por si só as unidades de mapeamento, com exceção para os Latossolos, com declividades médias de 3\% a 6\% e máxima de 19,15\%.

A avaliação e espacialização de textura de solos através da imagem de satélite são funcionais no delineamento das classes de textura. Contudo nota-se uma confusão entre as classes argilosa (35 a $\left.60 \mathrm{~g} \mathrm{~kg}^{-1}\right)$ e média argilosa ( $25 \mathrm{a}$ $\left.35 \mathrm{~g} \mathrm{~kg}^{-1}\right)$.

Os LV e RQ não são suficientemente diferenciados pelos aspectos de relevo, mas sim pelas informaçóes espectrais.

A integração de diferentes técnicas na identificação das classes de solos auxilia na convergência de evidências, que por sua vez, melhor identificam uma classe de solo.

\section{AGRADECIMENTOS}

Ao CNPq pela bolsa de pesquisa do $10^{\circ}$ autor e à Fundaçáo de Amparo à Pesquisa do Estado de Sáo Paulo (FAPESP) (05/60789-0) pela bolsa do 2. ${ }^{\circ}$ autor.

\section{REFERÊNCIAS}

ANDRONIKOV, V.L.; DOBROLVSHIY, G.V. Theory and methods for the use of remote sensing in the study of soils. Mapping Science and Remote Sensing, v.28, p.92-101, 1991.

ÂNGULO FILHO, R. Caracterização da drenagem e do relevo de três solos do estado de São Paulo através de fotografias aéreas e cartas planialtimétricas. 1986. 81f. Tese (Doutorado em Agronomia) Escola Superior de agricultura "Luiz de Queiroz", Universidade de Sáo Paulo, Piracicaba.
AL-ABBAS, A.H.; SWAIN, P.H.; BAUMGARDNER, M.F. Relating organic matter and clay content to multispectral radiance of soils. Soil Science, v.114, p.477-485, 1972.

CAMARGO, A.O.; MONIZ, A.C.; JORGE, J.A.; VALADARES, J.M. Métodos de análise química, mineralógica e física de solos do IAC. Campinas: Instituto Agronômico, 1986. 94p. (IAC. Boletim Técnico, 106)

CAMPOS, R.C.; DEMATTÊ, J.A.M. Cor do solo: uma abordagem da forma convencional de obtenção em oposição à automatização do método para fins de classificação de solos. Revista Brasileira de Ciência do Solo, v.28, p.853-863, 2004.

CAMPOS, M.C.C.; JÚNIOR, J.M.; PEREIRA G.T.; MONTANARI R.; CAMARGO, L.A. Relaçóes solo-paisagem em uma litoseqüência arenito-basalto na região de Pereira Barreto, SP. Revista Brasileira de Ciência do Solo, v.31, p.519-529, 2007.

CHRISTOFOLETTI, A. Geomorfologia. São Paulo: Universidade de São Paulo, 1974. 149p.

DEMATTÊ, J.A.M. O pedólogo e agricultura de precisão. Boletim Informativo da Sociedade Brasileira de Ciência do Solo, v.26, p.1719, 2001.

DEMATTÊ, J.A.M; BORGES, M.H.; PFEIFER, R.M. Aerofotos convencionais e imagens orbitais TM/LANDSAT no mapeamento morfopedológico em Santa Bárbara D Oeste (SP). Scientia Agricola, v.50, p.372-382, 1993.

DEMATTÊ, J.A.M.; CAMPOS, R.C.; ALVIS, M.C. Avaliaçâo espectral de solos desenvolvidos em uma toposequência de diabásio e folhelho da região de Piracicaba, SP. Pesquisa Agropecuária Brasileira, v.35, p.2447-2460, 2000.

DEMATTÊ, J.A.M.; DEMÉTRIO, V.A. Fotointerpretação de padrōes de drenagem em amostras circulares na caracterização de solos basálticos do estado do Paraná. Revista Brasileira de Ciência do Solo, v.20, p.109-115, 1996 .

DEMATTÊ, J.A.M.; DEMATTÊ, J.L.; CAMARGO, W.; FIORIO, P.R.; NANNI, M.R. Remote sensing in the recognition and mapping of tropical soils developed on topographic sequences. Mapping Sciences and Remote Sensing, v.38, p.79102, 2001.

DEMATTÊ, J.A.M.; DEMÉTRIO, V.A. Padróes de drenagem em áreas de solos desenvolvidos de rochas vulcânicas ácidas na região de Guarapuava (PR). Revista Brasileira de Ciência do Solo, v.20, p.305-311, 1996 b.

ESRI, 2004. ESRI, ArcGIS Desktop Developer Guide ArcGIS 9. ESRI Press, Redlands, California.

EMPRESA BRASILEIRA DE PESQUISA AGROPECUÁRIA. Sistema Brasileiro de Classificação de Solos. Brasília: Embrapa Produção de Informação, 2006. 306p.

FRANÇA, G.V.; DEMATTÊ, J.A.M. Parâmetros da rede de drenagem de solos da região de Iracemápolis (SP). Anais da Escola Superior de Agricultura "Luiz de Queiroz", v. 47, p.541-555, 1990. 
GENU, A.M.; DEMATTÊ, J.A.M. Informações espectroeletromagnéticas e topográficas na determinação de teores de componentes do solo. Bragantia, v.69, p.157-164, 2010.

IPPOLITI, G.A.R.; DA COSTA, L.M.; SCHAEFER, C.E.G.R.; FERNANDES FILHO, E.I.; GAGGERO, M.R. Análise digital do terreno: ferramenta na identificaçáo de pedoformas em microbacias na regiāo de "Mar De Morros" (MG). Revista Brasileira de Ciência do Solo, v.29, p.269-276, 2005.

IRVIN, B.J.; VENTURA, S.J.; SLATER, B.K. Fuzzy and isodata classification of landform elements from digital terrain data in Pleasant alley. Geoderma, v.77, p.137-154, 1997.

LEPSCH, I.F.; BUOL, S.W.; DANIELS, R.B. Soil-landscape relations in Occidental Plateau of São Paulo State, Brazil: I. Geomorphic surfaces and soil mapping units. Soil Science Society of America Journal, v. 41, p.104-115, 1977.

LUEDER, D.R. Aerial photographic interpretation: principles and applications. New York: MCGraw-Hill, 1959. 462p.

MADEIRA NETTO, J.S. Comportamento spectral dos solos. In: MENESES, P.R.; MADEIRA NETTO, J.S. (Org.). Sensoriamento Remoto: reflectância de alvos naturais. Brasília: Editora UnB; EMBRAPA Cerrados, 2001. p.127-156.

MIRANDA, E.E. (Coord.). Brasil em Relevo. Campinas: Embrapa Monitoramento por Satélite, 2005. Disponível em: <http://www. relevobr.cnpm.embrapa.br>. Acesso em: 7/10/2009.

\section{McBRATNEY, A.B.; MENDONÇA SANTOS, M.L.; MINASNY,} B. On digital soil mapping. Geoderma, v.117, p.3-52, 2003.

MOORE, I.D.; GRAYSON, R.B.; LADSON, A.R. Digital terrain modeling: a review of hydrological, geomorphological and biological applications. Hydrological Procedures, v.5, p.3-30, 1991.

ODEH, I.O.A.; McBRATNEY, A.B. Using AVHRR images for spatial prediction of clay content in the lower Namoi Valley of eastern Australia. Geoderma, v.97, p.237-254, 2000.
OLIVEIRA, J.B.; PRADO, H. Carta pedológica de Piracicaba. Campinas: Instituto Agronômico de Campinas, 1989. (Escala $1: 100.000)$.

OLIVEIRA, J.B.; JACOMINE, P.K.T.; CAMARGO, M.N. Classes gerais de solos do Brasil. Jaboticabal: FUNEP, 1992. 201 p.

PARVIS, M. Drainage pattern significance in airphoto identification of soils and bedrocks. Photogrammetric Engineering, v.16, p.387-408, 1950 .

PRADO, H. Manual de classificação de solos do Brasil. 2.ed. Jaboticabal: FUNEP, 1995. 197p.

RAIJ, B. van.; QUAGGIO, J.A.; CANTARELLA, H.; FERREIRA, M.E.; LOPES, A. S.; BATAGLIA. C.O. Análise química do solo para fins de fertilidade. Campinas: Fundação Cargill, 1989. $170 \mathrm{p}$.

REIS, T.E.S.; BARROS, O.N.F.; REIS, L.C. Utilização de sistema de informações geográficas para obtenção de cartas de solo e de declividade do município de Bandeirantes-PR. Geografia, v.13, p.1-17, 2004.

RICHARDS, J.A. Remote Sensing Digital Image Analysis. Berlin: Springer-Verlag, 1999. p.240.

SANTOS, R.D.; LEMOS, R.C.; SANTOS; H.G.; KER, J.C.; ANJOS, L.H.C. Manual de descriçấo e coleta de solo no campo. 5.ed. Viçosa: Sociedade Brasileira de Ciência do Solo, 2005. 100p.

SOUSA JUNIOR, J.G.A.; DEMATTÊ, J.A.M. Modelo digital de elevaçáo na caracterizaçáo de solos desenvolvidos de basalto e material arenítico. Revista Brasileira de Ciência do Solo, v.31, p.449-456, 2008.

VINK, A.D.A. Fotografias aéreas y lãs ciências del suelo. Delf: International Training Centre for Aerial Survey, 1963. 200p. 